\title{
The 1994 northern midlatitude budget of stratospheric chlorine derived from ATMOS/ATLAS-3 observations
}

\author{
R. Zander, ${ }^{1}$ E. Mahieu, ${ }^{1}$ M. R. Gunson, ${ }^{2}$ M. C. Abrams, ${ }^{3}$ A. Y. Chang, ${ }^{2}$ \\ M. Abbas, ${ }^{4}$ C. Aellig, ${ }^{5}$ A. Engel, ${ }^{6}$ A. Goldman, ${ }^{7}$ F. W. Irion, ${ }^{8}$ N. Kämpfer, ${ }^{9}$ \\ H. A. Michelsen, ${ }^{10}$ M. J. Newchurch, ${ }^{11}$ C. P. Rinsland, ${ }^{12}$ R. J. Salawitch, ${ }^{2}$ \\ G. P. Stiller, ${ }^{13}$ and G. C. Toon ${ }^{2}$
}

\begin{abstract}
Volume mixing ratio (VMR) profiles of the chlorine-bearing gases $\mathrm{HCl}, \mathrm{ClONO}_{2}, \mathrm{CCl}_{3} \mathrm{~F}, \mathrm{CCl}_{2} \mathrm{~F}_{2}$, $\mathrm{CHClF}_{2}, \mathrm{CCl}_{4}$, and $\mathrm{CH}_{3} \mathrm{Cl}$ have been measured between 3 and $49^{\circ}$ northern- and 65 to $72^{\circ}$ southern latitudes with the Atmospheric Trace MOlecule Spectroscopy (ATMOS) instrument during the ATmospheric Laboratory for Applications and Science (ATLAS)-3 shuttle mission of 3 to 12 November 1994. A subset of these profiles obtained between 20 and $49^{\circ} \mathrm{N}$ at sunset, combined with $\mathrm{ClO}$ profiles measured by the Millimeter-wave Atmospheric Sounder (MAS) also from aboard ATLAS-3, measurements by balloon for $\mathrm{HOCl}, \mathrm{CH}_{3} \mathrm{CCl}_{3}$ and $\mathrm{C}_{2} \mathrm{Cl}_{3} \mathrm{~F}_{3}$, and model calculations for $\mathrm{COClF}$ indicates that the mean burden of chlorine, $\mathrm{Cl}_{\text {TOT, }}$, was equal to $(3.53 \pm 0.10)$ ppbv (parts per billion by volume), 1sigma, throughout the stratosphere at the time of the ATLAS 3 mission. This is some $37 \%$ larger than the mean $2.58 \mathrm{ppbv}$ value measured by ATMOS within the same latitude zone during the Spacelab 3 flight of 29 April to 6 May 1985, consitent with an exponential growth rate of the chlorine loading in the stratosphere equal to $3.3 \% / y r$ or a linear increase of 0.10 ppbv/yr over the Spring-1985 to Fall-1994 time period. These findings are in agreement with both the burden and increase of the main anthropogenic Cl-bearing source gases at the surface during the 1980 s, confirming that the stratospheric chlorine loading is primarily of anthropogenic origin.
\end{abstract}

\section{Introduction}

The ATMOS experiment is a multi-mission, shuttle-based project designed for regular, detailed remote soundings of the Earth's middle atmosphere [Farmer, 1987; Gunson et al., 1996].

\footnotetext{
Institute of Astrophysics, University of Liège, Belgium

${ }^{2}$ Jet Propulsion Laboratory, California Institute of Technology, CA

${ }^{3}$ Science Applications International Corporation, Hampton, VA

${ }^{4}$ NASA Marshall Space Flight-Center, AL

${ }^{5}$ Naval Research Laboratory, Washington, DC

${ }^{6}$ Forschungszentrum, Jülich, Germany

${ }^{7}$ University of Denver, Denver, $\mathrm{CO}$

${ }^{8}$ California Institute of Technology, CA

${ }^{9}$ University of Bern, Switzerland

${ }^{10}$ Harvard University, Cambridge, MA

${ }^{11}$ University of Alabama, Huntsville, AL

12NASA Langley Research Center, Hampton, VA

${ }^{13}$ IMK-Forschungszentrum Karlsruhe, Germany
}

Copyright 1996 by the American Geophysical Union.

Paper number 96GL01792

0094-8534/96/96GL-01792\$05.00
During its first mission of 1985, ATMOS demonstrated the capability of establishing the budget of and partitioning among the nitrogen, chlorine and fluorine "families" [Russell et al., 1988; Zander et al., 1992] through infrared remote sensing from space. Subsequently, ATMOS was selected as a core instrument of the ATLAS program, performing additional missions in 1992, 1993 and 1994 [Gunson et al., 1996].

In this Letter, we report VMR profiles for the 7 most important Cl-bearing gases derived from a subset of ATMOS/ATLAS-3 sunset occultations observed at northern latitudes comparable to those covered during ATMOS/ Spacelab-3 in 1985. By complementing these with profiles of 4 additional, non-negligible chlorinated species measured by other experiments, and the COClF contribution from model calculations, we evaluate the 1994 stratospheric $\mathrm{Cl}$ budget and derive its rate of change between 1985 and 1994

\section{Data base and analysis}

The main absorption features used for VMR retrievals of the chlorine-bearing target molecules observed by ATMOS are primarily those reported in Table 1 of Zander et al. [1992]. This involves analyzing the ATMOS observations with the filters \# $12\left(600-1400 \mathrm{~cm}^{-1}\right), \# 9\left(600-2450 \mathrm{~cm}^{-1}\right)$ and \#3 $\left(1580-3420 \mathrm{~cm}^{-1}\right)$ which were used alternately during the ATLAS-3 mission in predetermined sequences during 68 sunset occultations that occurred between 20 and $49^{\circ} \mathrm{N}$. In order to appraise the latitudinal dependence of the VMR profiles, we subdivided this range into "midlatitude" (49 to $35^{\circ} \mathrm{N}$ ) and "subtropical" ( 35 to $20^{\circ} \mathrm{N}$ ) zones. The molecules $\mathrm{HCl}$ and $\mathrm{CH}_{3} \mathrm{Cl}$ are studied in filter 3 occultations, while all other ATMOS-retrieved gases are from Filter 9 and 12 events; to eliminate any biasing arising from the sampling of the ensembles of the filter 3 or the filter 9 and 12 occultations, we used $\mathrm{N}_{2} \mathrm{O}$ as a dynamical tracer to register $\mathrm{HCl}$ and $\mathrm{CH}_{3} \mathrm{Cl}$ profiles on the same vertical scale as the other gases.

The VMR profiles were retrieved with the ODS (Occultation Display Spectra) onion-peeling retrieval algorithm developed at JPL and described by Norton and Rinsland [1991]. The input data to the code and parameters necessary to retrieve consistent composition of the atmosphere are discussed by Gunson et al. [1996].

The adoption of temperature-dependent absorption crosssections for a number of heavy molecules such as $\mathrm{CCl}_{2} \mathrm{~F}_{2}$, $\mathrm{CCl}_{3} \mathrm{~F}, \mathrm{CHClF}_{2}$ and $\mathrm{ClONO}_{2}$, instead of more subjective parameters used before [Zander et al., 1987; Brown et al., 1987] greatly improved the absolute quality of related ATMOS retrievals used here [Brown et al., 1996]. 


\section{Results}

The mean $\mathrm{HCl}$ VMR value obtained by averaging all individual measurements made during the ATLAS-3 mission near and above $50 \mathrm{~km}$ altitude, and over the 3 to $49^{\circ} \mathrm{N}$ latitude zone was found equal to $(3.52 \pm 0.10) \mathrm{ppbv}$. Sub-binnings performed over the northern midlatitude and subtropical zones identified here indicate no statistically significant difference with respect to that mean, thus confirming that $\mathrm{HCl}$ is well mixed at the hemispheric level near and above the stratopause. Previous ATMOS missions also demonstrated that the VMR measurement of $\mathrm{HCl}$ in the vicinity of the stratopause is a good surrogate for total stratospheric chlorine loading [Zander et al., 1992; Gunson et al., 1994]. Therefore, the value of $(3.52 \pm 0.10) \mathrm{ppbv}$ for $\mathrm{HCl}$ near $50 \mathrm{~km}$ should represent the mean stratospheric loading of chlorine for the Fall-1994 time.

To corroborate this, we evaluated the burden of chlorine, $\mathrm{Cl}_{\text {ror, }}$ at various pressure levels by summing measured VMRs of the largest possible set of Cl-bearing gases (sources, sinks and reservoirs combined) weighted by the number of $\mathrm{Cl}$ atoms bound in each of them. For the ATLAS-3 time period, we performed the following summation:

$$
\begin{aligned}
\mathrm{Cl}_{\mathrm{TOT}} & =[\mathrm{HCl}]+\left[\mathrm{ClONO}_{2}\right]+4 \mathrm{x}\left[\mathrm{CCl}_{4}\right]+3 \mathrm{x}\left[\mathrm{CCl}_{3} \mathrm{~F}\right] \\
& +2 \mathrm{x}\left[\mathrm{CCl}_{2} \mathrm{~F}_{2}\right]+\left[\mathrm{CHClF}_{2}\right]+\left[\mathrm{CH}_{3} \mathrm{Cl}\right]+\{\mathrm{ClO}\} \\
& +3 \mathrm{x}\left\{\mathrm{CH}_{3} \mathrm{CCl}_{3}\right\}+3\left\{\mathrm{C}_{2} \mathrm{Cl}_{3} \mathrm{~F}_{3}\right\}+\{\mathrm{HOCl}\}+\{\{\mathrm{COClF}\}\}
\end{aligned}
$$

where the brackets indicate the VMRs of the seven important chlorinated constituents measured by ATMOS, and the 4 braces referring to VMRs of additional, non-negligible chlorine contributors not retrieved by ATMOS but by other experiments. In particular, the $\mathrm{ClO}$ data were derived from the MAS (Millimeter-wave Atmospheric Sounder) experiment [Croskey et al., 1992] which was also part of the ATL.AS-3 payload; details about the $\mathrm{ClO}$ data analysis have been

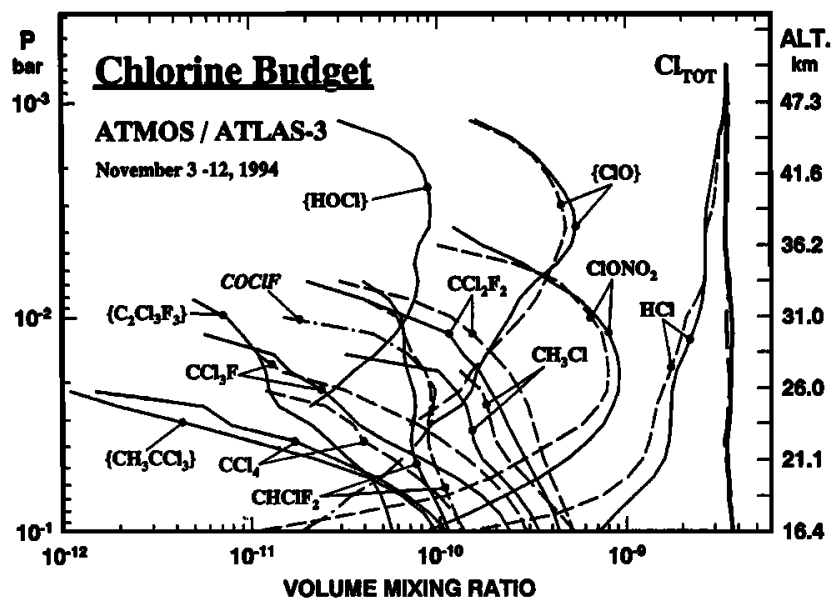

Figure 1. Graphical representation of the individual volume mixing ratio profiles included in the evaluation of the 1994 stratospheric Cl-loading for the northern midlatitude (35 to $49^{\circ} \mathrm{N}$; thin full lines) and subtropical ( 20 to $35^{\circ} \mathrm{N}$; thin dashed lines) zones. The thicker full and dashed lines display the corresponding $\mathrm{Cl}$ budgets throughout the stratosphere, sources, sinks and reservoirs combined. While all subtropical profiles experience uplifting, opposite relative contributions to $\mathrm{Cl}_{\text {TOT }}$ are noticeable between sources on one hand, and sinks and reservois on the other hand. For details, see text.

\begin{tabular}{|c|c|c|c|c|c|}
\hline \multirow{2}{*}{$\underset{\text { mbar }}{\mathrm{P}}$} & \multirow{2}{*}{$\begin{array}{l}\text { Approx. } \\
\text { Alt., } \mathrm{km}\end{array}$} & \multicolumn{2}{|c|}{ Midlatitudes } & \multicolumn{2}{|c|}{ Subtropics } \\
\hline & & $\mathrm{Cl}_{\text {TOT }}$ & $\mathrm{CCl}_{\mathrm{y}}$ & $\mathrm{Cl}_{\text {TOT }}$ & $\mathrm{CCl}_{\mathbf{y}}$ \\
\hline 0.68 & 50.2 & 3.52 & & 3.50 & \\
\hline 1.00 & 47.3 & 3.49 & & 3.52 & \\
\hline 1.47 & 44.4 & 3.47 & & 3.51 & \\
\hline 2.15 & 41.6 & 3.46 & & 3.55 & \\
\hline 3.16 & 38.9 & 3.45 & & 3.48 & \\
\hline 4.64 & 36.2 & 3.43 & 0.02 & 3.39 & \\
\hline 6.81 & 33.6 & 3.49 & 0.08 & 3.58 & 0.06 \\
\hline 10.00 & 31.0 & 3.65 & 0.22 & 3.41 & 0.31 \\
\hline 14.68 & 28.5 & 3.64 & 0.44 & 3.43 & 0.53 \\
\hline 21.54 & 26.0 & 3.62 & 0.69 & 3.57 & 0.98 \\
\hline 31.62 & 23.6 & 3.55 & 0.90 & 3.50 & 1.37 \\
\hline 46.42 & 21.2 & 3.49 & 1.34 & 3.43 & 1.86 \\
\hline 68.13 & 18.8 & 3.55 & 2.19 & 3.62 & 2.74 \\
\hline \multirow[t]{2}{*}{100.00} & 16.4 & $\underline{3.74}$ & 2.92 & 3.72 & 3.56 \\
\hline & Mean : & $3.54 \pm .09$ & & $3.52 \pm .09$ & \\
\hline
\end{tabular}

Table 1. Numerical values (in ppbv) for $\mathrm{Cl}_{\mathrm{Tot}}$ and $\mathrm{CCl}_{\mathrm{y}}$ at northern mid- and subtropical latitudes in November 1994

reported by Aellig et al. [1996]. The VMR profiles for $\mathrm{CH}_{3} \mathrm{CCl}_{3}$ and $\mathrm{C}_{2} \mathrm{Cl}_{3} \mathrm{~F}_{3}$ were derived from in situ measurements during a balloon flight performed by the Jülich group (A. Engel, private communication) in Aire-sur-l'Adour, France, on 7 October 1994, i.e., about one month prior to the ATLAS-3 mission. The $\mathrm{HOCl}$ profile was obtained from the analysis of sunset spectra recorded with the Mark IV FTIR during a balloon flight in September 1993 near 32 $\mathrm{N}$ (G.C. Toon, private communication), scaled by a $3 \%$ increase per year to represent the $\mathrm{HOCl}$ loading at the time of the ATLAS-3 mission. The double braced COCIF VMRs were extrapolated from model calculations by Kaye et al., [1991], assuming a 3\%/yr increase between their 1990 evaluations and 1994.

Figure 1 displays the profiles of the individual gases included in the present evaluation for both the midlatitude (thin full lines) and the subtropical (thin dotted lines) zones, as well as the corresponding total $\mathrm{Cl}$ profiles labeled $\mathrm{Cl}_{\mathrm{TOT}}$ displayed as thicker lines. For $\mathrm{CH}_{3} \mathrm{CCl}_{3}, \mathrm{C}_{2} \mathrm{Cl}_{3} \mathrm{~F}_{3}, \mathrm{HOCl}$ and $\mathrm{COCIF}$, the same profiles were used in both binnings, because of unavailable measurements for the two latitudinal zones.

Table 1 provides numerical values for $\mathrm{Cl}_{\text {Tor }}$ and $\mathrm{CCl}_{y}$, for the two northern midlatitude and subtropical zones; the pressure levels were selected among standard values adopted by various experiments (including UARS) for date archiving.

The VMRs of the top and bottom pressure levels of the midlatitude $\mathrm{Cl}_{\text {TOT }}$ profile (thick continuous line in Fig. 1) are equal, respectively, to 3.52 and $3.74 \mathrm{ppbv}$, with a corresponding mean VMR and standard deviation over the entire altitude span equal to $(3.54 \pm 0.09) \mathrm{ppbv}$. The extremes are indicative of a $6.3 \%$ decrease of $\mathrm{Cl}_{\mathrm{TOT}}$ which can be explained by the time delay for air to mix between 100 and 0.68 mbar $(\sim 16.5$ to $50 \mathrm{~km})$ levels.

The $\mathrm{Cl}_{\mathrm{T}}$ profile for the subtropical latitudinal zone (thick dotted line in Fig. 1) also indicates a decrease of $6.3 \%$ between bottom (3.72 ppbv) and top (3.50 ppbv) VMRs, with a corresponding mean mixing ratio and standard deviation equal to $(3.52 \pm 0.09)$ ppbv.

Figure 2 with its linear abscissa scale shows some details of the profiles of the key components which make up the $\mathrm{Cl}$ inventory for the northem midlatitude case $\left(35\right.$ to $\left.49^{\circ}\right)$. In particular, we have reproduced the $\mathrm{CCl}_{\mathrm{y}}$ curve corresponding 


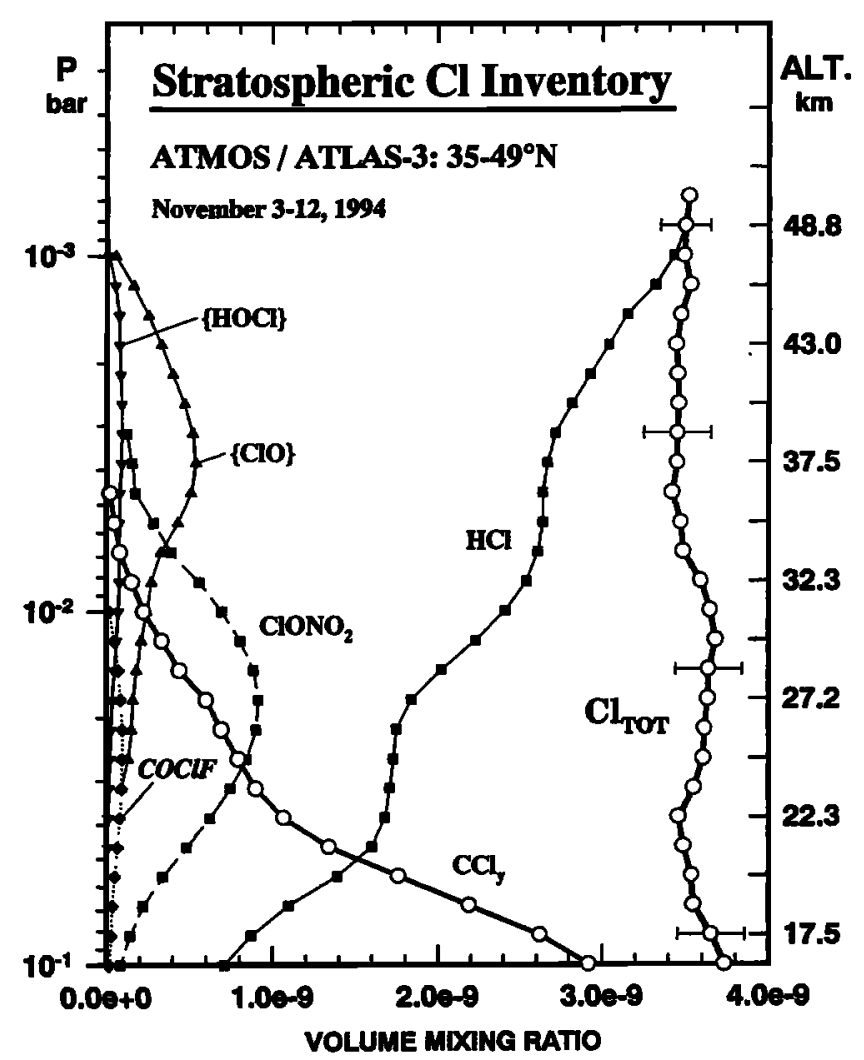

Figure 2. A linear-scale presentation of the key components entering in the total $\mathrm{Cl}$-loading evaluation throughout the stratosphere at northern midlatitudes. The $\mathrm{CCl}_{y}$ curve refers to the total chlorine bound in all organic source gases listed in the text. $\mathrm{Cl}_{\text {TOT }}$ represents the summation over $\mathrm{CCl}_{\mathrm{y}}, \mathrm{HCl}$, $\mathrm{ClONO}_{2}, \mathrm{ClO}, \mathrm{HOCl}$ and $\mathrm{COClF}$.

to the sum of $\mathrm{Cl}$ atoms bound in all source gases considered here. By further summing over $\mathrm{CCl}_{y}$ and the inorganic compounds $\mathrm{HCl}, \mathrm{ClONO}_{2}, \mathrm{ClO}, \mathrm{HOCl}$ and $\mathrm{COClF}$ also reproduced in Fig. 2, one obtains the thicker continuous curve which corresponds to the total chlorine loading $\mathrm{Cl}_{\text {TOT. }}$. Within the estimated uncertainty ranging from $4 \%$ at the top to $6 \%$ at the bottom of the $\mathrm{Cl}_{\text {TOT }}$ profile, the conservation of chlorine is properly demonstrated throughout the stratosphere. Within that uncertainty, however, we cannot rule out some missing, second order contributions from either reservoirs or sources not accounted for here. Some uncertainty in the spectroscopic parameters used to derive the profiles of the heavier molecules [see Brown et al., 1996 and Gunson et al., 1996] could also reflect in the lower altitude range.

\section{Discussion and conclusions}

The measurement of the budget of chlorine in the middle atmosphere involve a large number of Cl-bearing gases which cannot be studied by any one technique alone, and related investigations during the last years have sought approaches for its evaluation, based on a more limited number of measurements. These have generally invoked the work of Plumb and Ko [1992] who demonstrated that there exist compact correlations between the mixing ratios of long-lived atmospheric constituents, thus providing means of deriving the distribution versus altitude for some species, solely based on concentrations measured for others. The procedure has been applied in many cases [e.g., Schmidt et al., 1994; Woodbridge et al., 1995]. Among these, the application by Schmidt et al. [1994] is of relevance here; using $\mathrm{CCl}_{2} \mathrm{~F}_{2}$ as the "reference" gas, they derived the function

$$
\left[\mathrm{CCl}_{y}\right]=0.045 \times\left[\mathrm{CCl}_{2} \mathrm{~F}_{2}\right]^{182}+67.35
$$

in which the brackets refer to the VMRs of the related compounds, expressed in units of pptv ( $\left.\times 10^{-12} \mathrm{ppv}\right)$. Application of that formulation to the midlatitude mean $\mathrm{CCl}_{2} \mathrm{~F}_{2}$ profile derived in 1994 by ATMOS produces results which match very well the $\mathrm{CCl}_{\mathrm{y}}$ profiles obtained in this work, when accounting for the fact that Schmidt et al. [1994] sample species amounting to $95 \%$ of the total organic chlorine.

Model evaluations of the chlorine partitioning in the stratosphere as reported here for the ATLAS-3 mission are dealt with and discussed by Michelsen et al. [1996].

From the various independent results derived here, it can be concluded that the overall chlorine loading at the top of the stratosphere over the 20 to $49^{\circ} \mathrm{N}$ latitudinal zone was equal to $3.51 \mathrm{ppbv}$ at the time of the November 1994 ATLAS-3 mission, with a 1-sigma uncertainty of $0.15 \mathrm{ppbv}$ or $4 \%$; this uncertainty represents an estimated accuracy assessed as in previous investigations [Zander et al., 1990; Gunson et al., 1990]. Throughout the stratosphere, the $\mathrm{Cl}_{\text {TOT }}$ VMR profiles combining the important sources, sinks and reservoirs display consistent values which suggest only second order local deficit and a mean slope reflecting the time for air to mix from the lower to the upper stratosphere.

When compared to the mean stratospheric chlorine VMR of $2.58 \pm 0.10 \mathrm{ppbv}$ derived from the 1985 ATMOS/Spacelab3 mission [Zander et al., 1992], the present mean stratospheric chlorine loading of $3.53 \mathrm{ppbv}$ (see Table 1) corresponds to a $37 \%$ increase over the 9.5 years separating the two missions, i.e., an exponential rate of $3.3 \% / y r$ or a linear change of $0.10 \mathrm{ppbv} / \mathrm{yr}$. The mean stratospheric $\mathrm{Cl}$ VMR derived from the ATMOS/Spacelab-3 mission was shown to be in excellent agreement with the corresponding $1980 \mathrm{Cl}$ inventory in the lower troposphere [Zander et al., 1992], indicative of a mixing time of about 5 years for free tropospheric air to be transported and mixed throughout the stratosphere. The upper stratospheric $\mathrm{Cl}$ loading derived here (3.51 ppbv) for the time of the ATLAS-3 mission of November 1994 mirrors precisely the tropospheric $\mathrm{Cl}$ content that prevailed in 1989-90 [WMO Reports No. 25, 1992 and NASA Pub. 1339, 1994], thus confirming the 4-5 year lag time between tropospheric and stratospheric chlorine loading identity. In addition, the rate of change of $3.3 \% / y$ deduced here agrees very well with the increase of the organic chlorine burden in the lower troposphere (i.e., $0.104 \mathrm{ppbv}$ for a total of $3.18 \mathrm{ppbv}$ in 1986 and $0.109 \mathrm{ppbv}$ for a total loading of 3.46 ppbv in 1989; see WMO Reports No. 18, 1989 and No. 25, 1992).

As a consequence of the excellent agreement between the stratospheric chlorine loadings and rates of change derived from the ATMOS missions of 1985 and 1994 and the surface measurements of Cl-bearing gases some 4-5 years earlier, there remains no doubt that the bulk of stratospheric chlorine and its evolution are primarily associated with the release at the ground of chlorinated source gases produced industrially. As concluded by Gunson et al. [1994], this implies that natural sources of chlorine, in particular $\mathrm{CH}_{3} \mathrm{Cl}$ and perhaps 
$\mathrm{CCl}_{4}$, and volcanic activity, have contributed negligibly to the changes in the burden of stratopheric $\mathrm{Cl}$ over the last decade or so.

The 1987 Montreal Protocol and its London and Copenhagen Amendments are intended to reduce the future levels of atmospheric chlorine by regulating the production and release in the atmosphere of the most important anthropogenic, Cl-bearing source gases at the ground, primarily the chlorofluorocarbons (CFCs). The successive ATMOS missions have provided, thus far, the most consistent and complete set of measurements needed to "watch" the timely chlorine loading and to model its impact on ozone depletion throughout the entire stratosphere. Similar measurements will become critical in the near future when the stratospheric loading is expected to start decreasing, to test the implementation of the Protocol and the validity of the model predictions.

Acknowledgements This work was carried out at the Jet Propulsion Laboratory (JPL), California Institute of Technology, under contract with the National Aeronautics and Space Administration (NASA). The University of Liège involvement in the ATMOS project was partly supported within the frame of the Belgian 'Global Change' program coordinated by the S.S.T.C., Brussels.

\section{References}

Aellig, C. P., et al., Latitudinal Distribution of upper stratospheric ClO as derived from space borne microwave spectroscopy, this issue, 1996.

Brown, L. R., et al., Molecular line parameters for the atmospheric trace molecule spectroscopy (ATMOS) experiment, Appl. Opt., 26, 5154-5182, 1987.

Brown, L. R., et al., The 1995 Atmospheric Trace Molecule Spectroscopy (ATMOS) linelist, Appl. Opt., in press, 1996.

Croskey, C. L., et al., The Millimeter Wave Atmospheric Sounder (MAS): a Shuttle-based remote sensing experiment, IEEE Transactions on Geoscience and Remote Sensing, 40, 1090-1100, 1992.

Farmer, C. B., High resolution infrared spectroscopy of the sun and the earths atmosphere from space, Microchim. Acta/Wien/lI, 189$214,1987$.

Gunson, M. R., et al., Measurements of $\mathrm{CH}_{4}, \mathrm{~N}_{2} \mathrm{O}, \mathrm{CO}, \mathrm{H}_{2} \mathrm{O}$, and $\mathrm{O}_{3}$ in the middle atmosphere by the Atmospheric Trace Molecule Spectroscopy experiment on Spacelab 3, J. Geophys. Res.,95, 13867-13882, 1990.

Gunson, M. R., et al., Increase in levels of stratospheric chlorine and fluorine loading between 1985 and 1992, Geophys. Res. Lett., 21, 2223-2226, 1994.

Gunson, M. R., et al., The Atmospheric Trace Molecule Spectroscopy (ATMOS) experiment deployment on the ATLAS-3 Space Shuttle Mission, Geophys. Res. Lett., this issue, 1996.

Kaye, J. A., et al., Two-dimensional model calculations of fluorinecontaining reservoir species in the stratosphere, J. Geophys. Res., $96,12,865-12,881,1991$

Michelsen, H. A., et al., Chlorine partitioning in the stratosphere: evidence from ATMOS measurements for an additional source of $\mathrm{HCl}$, Geophys. Res. Lett., this issue, 1996.
NASA Reference Publication 1339, Report on Concentrations, Lifetimes and Trends of CFCs, Halons and Related Species, J.A. Kaye, S.A Penkett and F.M. Ormond, eds., NASA Office of Missions to Planet Earth, Science Div., Washington, D.C., January 1994.

Norton, R. H., and C. P. Rinsland, ATMOS data processing and science analysis methods, Appl. Opt., 30, 389-400, 1991.

Plumb, R. A., and M. K. W. Ko, Interrelationships between mixing ratios of long-lived constituents, J. Geophys. Res., 95, 1014510156, 1992.

Russell III, J. M., et al., Measurements of odd nitrogen compounds in the stratosphere by the ATMOS experiment on Spacelab 3, $J$. Geophys. Res., 93, 1718-1736, 1988.

Schmidt, U., et al., The variation of available chlorine, $\mathrm{Cl}_{\mathrm{y}}$, in the Arctic polar vortex during EASOE, Geophys. Res. Lett., 21, 1215 1218, 1994.

WMO-Report No. 18, Report of the International Ozone trends Panel-1988, World Meteorological Organization, P.O. Box 5, CH 1211, Geneva 20, Switzerland, 1989.

WMO-Report No. 25, Scientific Assessment of Ozone Depletion: 1991. World Meteorological Organization, P.O. Box 2300, Geneva 2, CH 1211, Switzerland, 1992.

Woodbridge, E. L., et al., Estimates of total organic and inorganic chlorine in the lower stratosphere from in situ and flask measurements during AASE II, J. Geophys. Res., 100, 3057-2064, 1995.

Zander, R., et al., Stratospheric $\mathrm{ClONO}_{2}, \mathrm{HCl}$ and $\mathrm{HF}$ concentration profiles derived from ATMOS/Spacelab 3 observations - An update, J. Geophys. Res., 95, 20519-20525, 1990.

Zander, R., et al., Infrared spectroscopic measurements of halogenated source gases in the stratosphere with the ATMOS instrument, $J$. Geophys. Res., 92, 9836-9850, 1987.

Zander, R., et al., The 1985 chlorine and fluorine inventories in the stratosphere based on ATMOS observations at $30^{\circ}$ North latitude, J. Atmos. Chem., 15, 171-186, 1992.

M. M Abbas, ESSL, NASA-MSFC, Huntsville, AL 35889

M. C. Abrams, NASA-LaRC, Mail Stop 475, VA 23681-0001

C. Aellig, Naval Research Laboratory, Code 7227, Washington, DC 20375

A. Y. Chang, M. R. Gunson, R. J. Salawitch, and G. C. Toon, JPL, 4800 Oak Grove Drive, Pasadena, CA 91109

A. Engel, Jảlich Forschungszentrum, ICG3, D-5170 Jalich, Germany

A. Goldman, Dep. of Physics, Univ. of Denver, CO 80208

F. W. Irion, Dep. of Chemical Engineering, Caltech, Pasadena, CA 91125

N. Kămpfer, Institute of Applied Physics, Univ.of Bern, Bern, Switzerland

H. A. Michelsen, Dep. of Earth and Planetary Sciences, Harvard Univ., Cambridge, MA 02138

E. Mahieu, and R. Zander, Institute of Astrophysics, Univ. of Liège, 4000 Liège, Belgium

M. J. Newchurch, Univ.of Alabama at Huntsville, Huntsville AL 35899

C. P. Rinsland, NASA-LaRC, Mail Stop 401A, Hampton, VA 23681-0001

G. P. Stiller, IMK-Forschungszentrum, Karlsruhe, Germany.

(Received September 20, 1995; revised March 8, 1996; accepted May 2, 1996.) 